\title{
Mechanism and Kinetics of the Photocatalyzed Oxidation of $p$-Phenylenediamines by Peroxydisulfate in the Presence of Tri-2,2'-bipyridylylruthenium(II)
}

\author{
Ulrich Nickel," Yao-Hong Chen, and Siegfried Schneider \\ Institute of Physical and Theoretical Chemistry, University of Erlangen-Nuremberg, \\ Egerlandstrasse 3, D-91058 Erlangen, Germany
}

Maria I. Silva, Hugh D. Burrows, and Sebastião J. Formosinho

Chemistry Department, University of Coimbra, 3049 Coimbra, Portugal

Received: September 20, 1993; In Final Form: January 4, $1994^{\circ}$

\begin{abstract}
The autocatalytic oxidation of $p$-phenylenediamines with peroxydisulfate can be strongly enhanced by irradiation in the presence of tri-2,2'-bipyridylylruthenium(II). $\mathrm{Ru}(\mathrm{bpy}) 3^{2+}$ acts as photosensitizer and photocatalyst. First, $\mathrm{Ru}(\mathrm{bpy})_{3}{ }^{3+}$ is formed by quenching excited $\mathrm{Ru}^{*}(\mathrm{bpy})_{3}{ }^{2+}$ with $\mathrm{S}_{2} \mathrm{O}_{8}{ }^{2-}$. Then the ruthenium(III) complex oxidizes $p$-phenylenediamine. The resulting $\mathrm{Ru}(\mathrm{bpy})_{3}{ }^{2+}$ can start the cycle again. The photocatalytic oxidation of $N, N$-diethyl-p-phenylenediamine as well as the dark reactions were studied with stopped-flow techniques. The mechanism of this complex reaction is discussed in detail.
\end{abstract}

\section{Introduction}

Following initial studies on the $\mathrm{Ru}(\mathrm{bpy})_{3}{ }^{2+}$ complex, the chemistry of the excited electronic states of diimine-substituted $d^{6}$ metal complexes has been extensively studied and has found application in a large number of areas, with both the parent complex and its derivatives. Many researchers ${ }^{1-5}$ have been attracted by the combination of the ground-state chemical stability, excited-state reactivity, luminescence emission, and redox properties of these compounds.

$\mathrm{Ru}(\mathrm{bpy})_{3}{ }^{2+}$ photoluminescence ${ }^{6-8}$ can give information both about quencher molecules nearby and about the microenvironment around the probe. ${ }^{9}$ For example, the concentration of oxygen can be determined since $\mathrm{O}_{2}$ is an efficient quencher for the ruthenium complexes. ${ }^{10,11}$

Furthermore, the lowest excited triplet state has a reasonably long lifetime. ${ }^{12}$ As the $\mathrm{Ru}^{*}$ (bpy) ${ }_{3}{ }^{2+}$ complex is easily oxidized and reduced, $, 6,6,13$ it has found use as the chromophore of choice in areas as diverse as solar energy conversion ${ }^{8,14-17}$ and as a test of theories of photoinduced electron-transfer reactions. ${ }^{13,18-20}$

The photoinduced chemistry occurs from the lowest excited state, which is a triplet, and involves a MLCT transition. The exact nature of this state is still the subject of extensive research. 2,7,8,10,14,21,22 Electron-transfer reactions of this species may involve either the oxidation or reduction of the excited state of $\mathrm{Ru}$ (bpy) $3^{2+}{ }^{2}$ with the dominant process depending on thermodynamic parameters such as the oxidation potentials of the $\mathrm{Ru}^{*}(\mathrm{bpy})_{3}{ }^{2+} / \mathrm{Ru}(\mathrm{bpy})_{3}{ }^{3+}$ and $\mathrm{Ru} *(\mathrm{bpy})_{3}{ }^{2+} / \mathrm{Ru}(\mathrm{bpy})_{3}{ }^{+}$couples and on the zero-zero transition energy, ${ }^{3} E^{0-0}$.

Peroxydisulfate ion, $\mathrm{S}_{2} \mathrm{O}_{8}{ }^{2-}$, is one of the most useful oxidative quenchers of excited $\mathrm{Ru}(\mathrm{bpy})_{3}{ }^{2+23-25}$ because it decomposes into two ions upon photoreduction, thus minimizing the back-electrontransfer reaction. The photoexcited ruthenium(II) complex is rapidly quenched by the peroxydisulfate ion by both static and dynamic processes ${ }^{26}$ generating $\mathrm{Ru}(\mathrm{bpy})_{3}{ }^{3+}, \mathrm{SO}_{4}{ }^{2-}$, and $\mathrm{SO}_{4}{ }^{\circ-}$. Like $\mathrm{Ru}(\text { bpy })_{3}{ }^{3+}, \mathrm{SO}_{4}{ }^{--}$is also a strong oxidant ${ }^{23,27,28}$ and is able to oxidize various organic and inorganic compounds.

The reduced form $\mathrm{SO}_{4}{ }^{2-}$ is practically inert and is not considered to be a pollutant. Therefore, peroxydisulfate ion is an ideal candidate for technological application, e.g., in the photographic bleach process (to oxidize silver) or in certain dye formation processes (such as oxidation of $\mathrm{N}$-substituted p-phen-

- Abstract published in Advance ACS Abstracts, February 15, 1994. ylenediamines). ${ }^{29-31}$ In thermal reactions, the peroxydisulfate ion oxidizes substrates only slowly, although its redox potential is very high. $24,27,32$ The oxidation rate can often be increased by adding certain metal ions or metal complexes. ${ }^{32-35}$

No acceleration of the redox reaction between $\mathrm{N}$-substituted $p$-phenylenediamines and peroxydisulfate was observed with ruthenium(II) complexes in the dark. However, during irradiation a strong increase of the initial reaction rate was observed. This paper deals with the mechanism and the kinetics of both the autocatalytic dark reaction and the photocatalyzed oxidation of $N, N$-diethyl-p-phenylenediamine by peroxydisulfate in the presence of $\mathrm{Ru}(\mathrm{bpy}) 3^{2+}$.

\section{Experimental Section}

$N, N$-Diethyl-p-phenylenediamine- $\mathrm{H}_{2} \mathrm{SO}_{4}, N, N$-dimethyl-pphenylenediamine $2 \mathrm{HCl}$, and potassium peroxydisulfate were p.a. reagents from Merck; $N, N, N^{\prime}, N^{\prime}$-tetramethyl-p-phenylenediamine. $2 \mathrm{HCl}$ and the $\mathrm{Ru}(\mathrm{bpy})_{3} \mathrm{Cl}_{2} \cdot 6 \mathrm{H}_{2} \mathrm{O}$ were $\mathrm{p}$.a. reagents from Fluka. All compounds were used without further purification, but the purity of the $p$-phenylenediamines (99\%) was controlled spectrophotometrically.

The buffer solutions were prepared according to Sørensen from $\mathrm{KH}_{2} \mathrm{PO}_{4}$ and $\mathrm{Na}_{2} \mathrm{HPO}_{4}$ (Merck). Organic buffer compounds such as citrate could not be used because they are slowly oxidized by peroxydisulfate. ${ }^{29}$ All solutions were prepared immediately before use with doubly distilled water. They were degassed in an ultrasonic bath under water jet vacuum followed by saturation with nitrogen. This procedure was carried out three times. Finally, the solutions were kept under argon to avoid any contamination with oxygen. Slow kinetics experiments were carried out in a Kontron Uvikon 810 spectrophotometer by mixing the reactants rapidly with special pipets (Eppendorf). Fast reactions were followed in a homemade stopped-flow apparatus with optical detection. ${ }^{36}$

$\mathrm{Ru}$ (bpy) $3_{3}{ }^{3+}$ was formed by irradiation of solutions containing both $\mathrm{Ru}(\mathrm{bpy})_{3}{ }^{2+}$ and peroxydisulfate with a xenon $(150 \mathrm{~W})$ or tungsten lamp (100 W). To avoid the photoinduced direct oxidation of $p$-phenylenediamine with peroxydisulfate UV light with wavelengths $<300 \mathrm{~nm}$ was absorbed with a $7-\mathrm{mm}$ polystyrene filter.

Excited-state quenching studies of the aqueous solution of $\mathrm{Ru}-$ (bpy) $3^{2+}$ were made using a SPEX DM $3000 \mathrm{~F}$ spectrofluorimeter at an excitation wavelength of $452 \mathrm{~nm}$. Oxygen was removed 


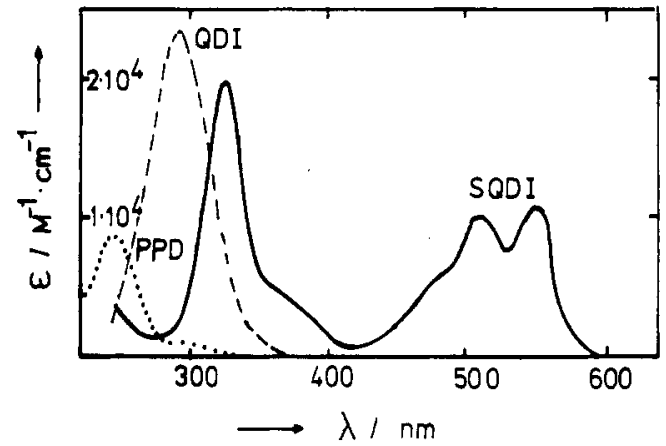

Figure 1. Spectra of $N, N$-diethyl-p-phenylenediamine (PPD) and its oxidation products (SQDI and QDI).

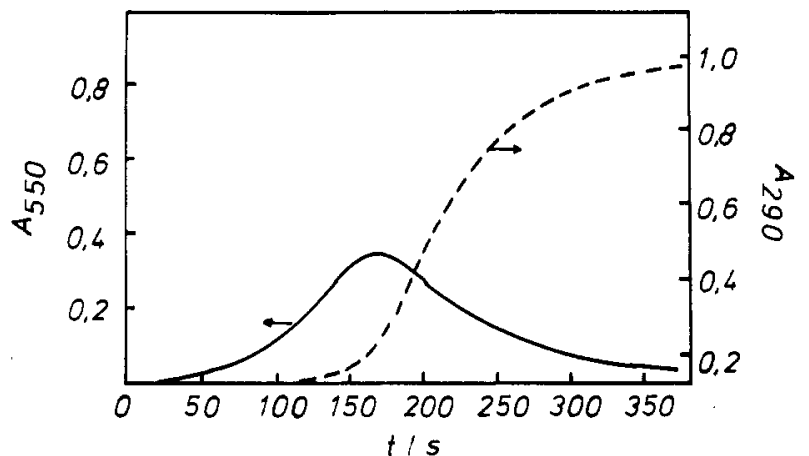

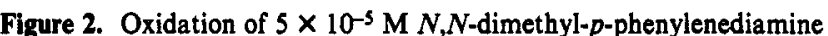
by $1 \times 10^{-4} \mathrm{M} \mathrm{K}_{2} \mathrm{~S}_{2} \mathrm{O}_{8}$ in water, $\mathrm{pH} \approx 4$. The full line (recorded at $\lambda$ $=550 \mathrm{~nm}$ ) describes the formation of SQDI, the dashed line (recorded at $290 \mathrm{~nm}$ ) predominantly corresponds to the formation of QDI. $l=1$ $\mathrm{cm}, 25^{\circ} \mathrm{C}$.

\section{SCHEME 1}

$$
\begin{gathered}
\mathrm{PPDH}^{+} \stackrel{-\mathrm{H}^{+}}{\rightleftharpoons} \mathrm{PPD} \stackrel{\mathrm{S}_{2} \mathrm{O}_{8}^{2-}, k_{1}}{\longrightarrow} \mathrm{SODI} \stackrel{\mathrm{S}_{2} \mathrm{O}_{8}{ }^{2-}, k_{2}}{\longrightarrow} \mathrm{ODI} \\
\mathrm{H}^{+}+\mathrm{PPD}+\mathrm{ODI} \longrightarrow 2 \mathrm{OODI}
\end{gathered}
$$

from solutions in this case by bubbling with pure nitrogen gas for at least $20 \mathrm{~min}$.

All experiments were carried out at $21 \pm 2{ }^{\circ} \mathrm{C}$.

\section{Results and Discussion}

Autocatalytic Dark Reaction. The oxidation of $\mathrm{N}$-alkylated $p$-phenylenediamines (PPD) can be easily followed spectrophotometrically due to the strong and characteristic absorbance of the first oxidation product, $p$-semiquinonediimine (SQDI), in the visible region of the spectrum. Both PPD and its totally oxidized form, $p$-quinonediimine (QDI), absorb only in the UV region. Figure 1 shows the spectra of $N, N$-diethyl-p-phenylenedimine and the two oxidized forms. 37,38

The dark redox reaction between $p$-phenylenediamines and peroxydisulfate occurs autocatalytically. ${ }^{29,33}$ Induction periods are observed for the formation of both the semioxidized and the totally oxidized form. A typical example is displayed in Figure 2.

The kinetics and mechanism of this autocatalytic reaction have been described in a previous paper. ${ }^{29}$ The most important steps are summarized in Scheme 1. The reaction begins with the oxidation of the unprotonated form (PPD) by $\mathrm{S}_{2} \mathrm{O}_{8}{ }^{2-}$. The protonated form $\left(\mathrm{PPDH}^{+}\right)$is not significantly attacked by most oxidants, including $\mathrm{S}_{2} \mathrm{O}_{8}{ }^{2-}$. Due to the rather high value of the first protonation constant of $N, N$-diethyl-p-phenylenediamine ( $K$ $\left.=\left[\mathrm{PPDH}^{+}\right] /[\mathrm{PPD}]\left[\mathrm{H}^{+}\right]=1.0 \times 10^{8} \mathrm{M}^{-1}\right),{ }^{38}$ at $\mathrm{pH}<5$ the concentration of PPD is much smaller than that of $\mathrm{PPDH}^{+}$. Therefore, the formation of SQDI and QDI begins slowly. However, the QDI thus formed reacts rapidly with both PPD and $\mathrm{PPDH}^{+}$to generate two molecules of SQDI. Thus an autocat-

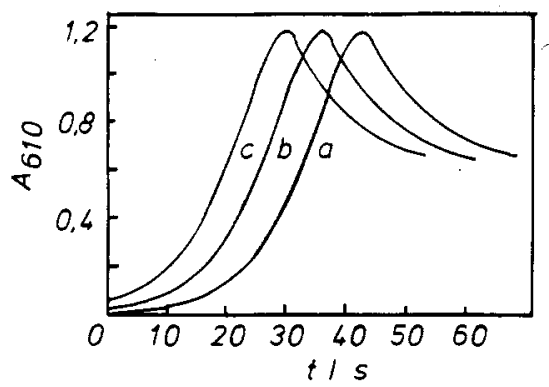

Figure 3. Influence of hexacyanoferrate on the induction period of the reaction between $1 \times 10^{-4} \mathrm{M} N, N, N^{\prime}, N^{\prime}$-tetramethyl-p-phenylenediamine and $1.25 \times 10^{-4} \mathrm{M} \mathrm{K}_{2} \mathrm{~S}_{2} \mathrm{O}_{8}$ in water $\mathrm{pH} \approx 4 . l=1 \mathrm{~cm}, 25^{\circ} \mathrm{C}$. $\left[\mathrm{K}_{3}-\right.$ $\left.\mathrm{Fe}(\mathrm{CN})_{6}\right]=0$ (a), $5 \times 10^{-7} \mathrm{M}(\mathrm{b})$ and $2.5 \times 10^{-6} \mathrm{M}(\mathrm{c})$.

alytic acceleration of the reaction occurs. Eventually PPD (and $\mathrm{PPDH}^{+}$) reacts predominantly with QDI while peroxydisulfate mainly oxidizes SQDI.

Despite this autocatalytic reaction, the net formation of QDI can of ten be neglected by use of an excess of $p$-phenylenediamine. Then, according to the Beer-Lambert law, and taking into account the fact that peroxydisulfate accepts two electrons, the maximum absorbance $\left(A_{\max }\right)$ directly allows the determination of the initial concentration of the oxidant $\left[\mathrm{S}_{2} \mathrm{O}_{8}{ }^{2-}\right]_{0}$ provided $[\mathrm{PPD}]_{0} \gg$ $\left[\mathrm{S}_{2} \mathrm{O}_{8}{ }^{2-}\right]_{0}$, where $[\mathrm{PPD}]_{0}$ is the initial concentration of both PPD and $\mathrm{PPDH}^{+}$:

$$
A_{\max }=2 \epsilon_{\mathrm{S}} l\left[\mathrm{~S}_{2} \mathrm{O}_{8}{ }^{2-}\right]_{0}
$$

with $\epsilon_{\mathrm{S}}=$ absorption coefficient of SQDI (in $\mathrm{M}^{-1} \mathrm{~cm}^{-1}$ ) and $l=$ path length of the cuvette.

Acceleration of the Dark Reaction by Supporting Oxidants. Despite its high redox potential ( $2.0 \mathrm{~V}$ vs NHE), ${ }^{24,27}$ peroxydisulfate oxidizes $p$-phenylenediamines only slowly. The rate of oxidation can sometimes be enhanced by the addition of compounds which rapidly oxidize such as hexacyanoferrate(III), iodine, or certain cobalt(III) complexes. ${ }^{33}$ But as the redox reaction between the reduced form of these supporting oxidants and peroxydisulfate also occurs very slowly, usually no redox catalysis is observed. Instead, only a shortening of the induction period is obtained due to the rapid formation of $p$-semiquinonediimine with the auxiliary oxidant. Some examples for this acceleration with $\mathrm{Fe}(\mathrm{CN})_{6}{ }^{3-}$ as supporting oxidizing agent are shown in Figure 3. The concentration of the rapidly formed $p$-semiquinonediimine approaches that of the initial concentration of hexacyanoferrate, because each ion of this oxidant accepts only one electron. The more hexacyanoferrate is added, the higher the initial concentration of SQDI and, with it, the quasi-initial reaction rate of the autocatalytic oxidation of $p$-phenylenediamine by peroxydisulfate.

A similar shortening of the induction period could be obtained with ruthenium(III) complexes. Figure 4 shows some examples for the oxidation of $N, N$-diethyl-p-phenylenediamine with peroxydisulfate in the presence of $\mathrm{Ru}(\mathrm{bpy}){ }_{3}{ }^{3+}$. The ruthenium(III) complex was prepared by irradiation of an aqueous solution of $\mathrm{Ru}(\mathrm{bpy})_{3}{ }^{2+}$ in the presence of peroxydisulfate. The quasi-initial concentration of SQDI equals the concentration of $\mathrm{Ru}(\mathrm{bpy}) \mathrm{s}^{3+}$ produced during the irradiation by peroxydisulfate (each molecule of $\mathrm{Ru}$ (bpy) $3^{3+}$ accepts one electron).

Acceleration of the Oxidation by Irradiating in the Presence of $\mathbf{R u}(\mathrm{bpy}) \mathbf{3}^{2+}$. In contrast to these apparent catalytic reactions, real catalysis was obtained by irradiating a mixture of $p$ phenylenediamine, peroxydisulfate, and $R u(b p y)_{3}{ }^{2+}$. Usually peroxydisulfate was premixed with $R u(b p y){ }_{3}{ }^{2+}$, then PPD added, and the photocatalytic reaction started by switching on the irradiation. While the solution was being irradiated, the increase of absorbance at $550 \mathrm{~nm}$ due to the formation of SQDI could not be measured in our apparatus. The course of the reaction was therefore recorded only after the irradiation was stopped. Figure 


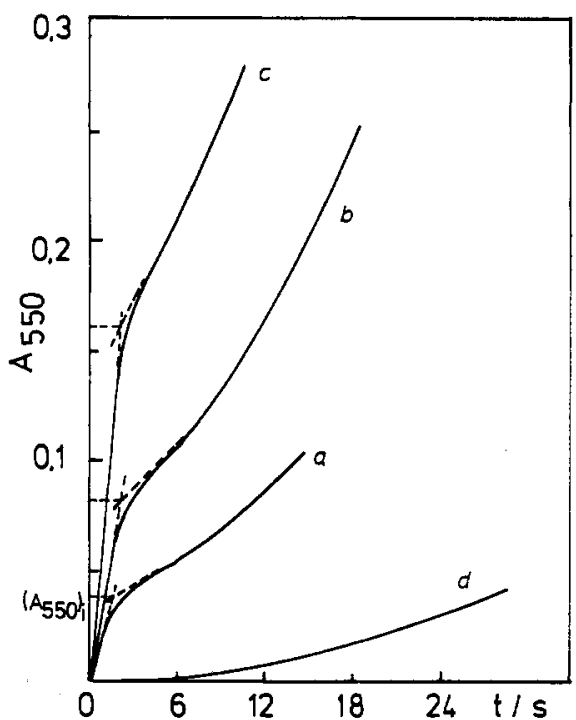

Figure 4. Absorbance-time curves for the formation of SQDI after the addition of $N, N$-diethyl-p-phenylenediamine to a mixture of $\mathrm{K}_{2} \mathrm{~S}_{2} \mathrm{O}_{8}$ and $\mathrm{Ru}$ (bpy) ${ }_{3}{ }^{2+}$ which had been irradiated for $20 \mathrm{~s}$ with a xenon lamp in order to produce $\mathrm{Ru}(\mathrm{bpy}) 3^{3+}$ (curves a-c). $[\mathrm{PPD}]=1 \times 10^{-3} \mathrm{M},\left[\mathrm{K}_{2} \mathrm{~S}_{2} \mathrm{O}_{8}\right]$ $=1 \times 10^{-3} \mathrm{M},\left[\mathrm{Ru}(\mathrm{bpy}) 3^{2+}\right]=1.25 \times 10^{-5} \mathrm{M}(\mathrm{a}), 2.5 \times 10^{-5} \mathrm{M}$ (b), $\times 10^{-5} \mathrm{M}$ (c) and (d). Curve $\mathrm{d}$ was recorded without irradiation, i.e., with RuII instead of RuIII, $\lambda=550 \mathrm{~nm}, l=1 \mathrm{~cm}$.

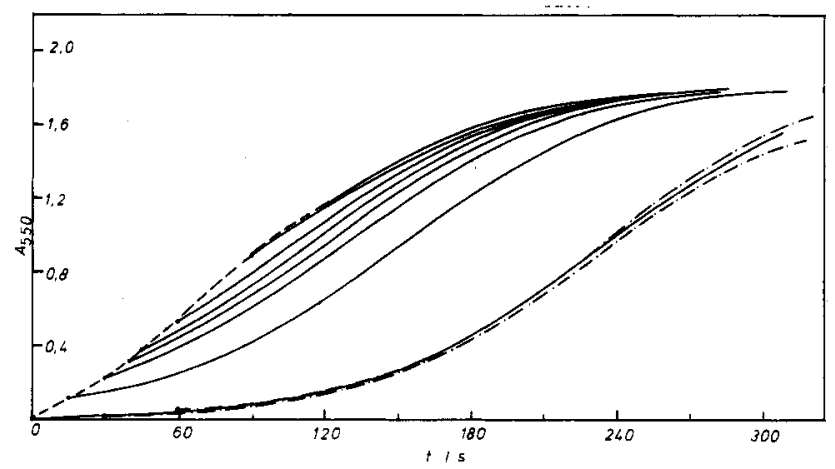

Figure 5. Dependence of the absorbance on the irradiation time for a mixture of $N, N$-diethyl-p-phenylenediamine $\left(2 \times 10^{-3} \mathrm{M}\right), \mathrm{Ru}(\mathrm{bpy}){ }_{3}{ }^{2+}$ $\left(1.3 \times 10^{-6} \mathrm{M}\right)$ and $\mathrm{K}_{2} \mathrm{~S}_{2} \mathrm{O}_{8}\left(1 \times 10^{-4} \mathrm{M}\right) . \lambda=550 \mathrm{~nm}, l=1 \mathrm{~cm}$. Irradiation period (dashed line) and dark reaction (full line). Full line curves: recorded immediately after interrupting the irradiation. Dashdotted line: in the absence of $R u(b p y){ }_{3}{ }^{2+}$ as well as in the presence of $\mathrm{Ru}(\mathrm{bpy})_{3}{ }^{2+}$, but without the irradiation; dashed line: the formation of SQDI during the irradiation.

5 shows some absorbance/time curves of this kind for varying irradiation times.

The dashed line in Figure 5, which connects the values of absorbance recorded immediately after stopping the irradiation, describes the formation rate of $p$-semiquinonediimine during the irradiation. A comparison with the results displayed in Figure 4 shows that the shortening of the induction period obtained would need a much higher concentration of the ruthenium complex than that used. However, a 10 -fold higher amount of ruthenium complex not only shortened the induction period but also accelerated the autocatalytic formation of SQDI. On the other hand, only little acceleration was observed on irradiation in the absence of any bipyridylruthenium ions (dash-dotted line). Furthermore, no acceleration could be obtained by the addition of even a high concentration of $\mathrm{Ru}(\mathrm{bpy}) 3^{2+}\left(10^{-4} \mathrm{M}\right)$ in the dark. Under steady illumination, the reaction rate increased with increasing concentration of both $\mathrm{Ru}(\mathrm{bpy}) \mathrm{3}^{2+}$ and peroxydisulfate, but was almost independent of the concentration of $p$-phenylenediamine.

Scheme 2 shows some of the reactions which might be responsible for this photocatalytic reaction. The excited ruthenium complex, $\mathrm{Ru}^{*}(\mathrm{bpy})_{3}{ }^{2+}$, transfers an electron to the per-

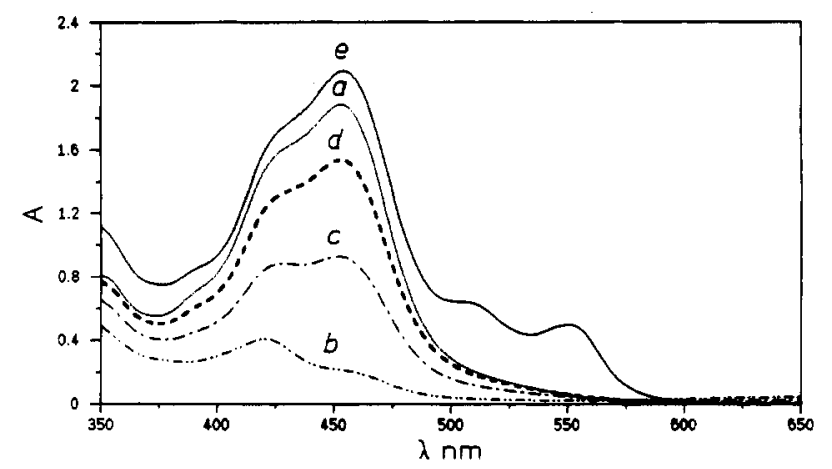

Figure 6. UV-vis spectra showing Ru(bpy) ${ }_{3}{ }^{2+}$ regeneration, $N, N$-diethyl$p$-phenylenediamine was added after irradiating a mixture of $\mathrm{K}_{2} \mathrm{~S}_{2} \mathrm{O}_{8}$ and Ru(bpy) $3^{2+}$ for $\tau \mathrm{s} . \quad l=1 \mathrm{~cm}$ (see Table 1$)$.

SCHEME 2

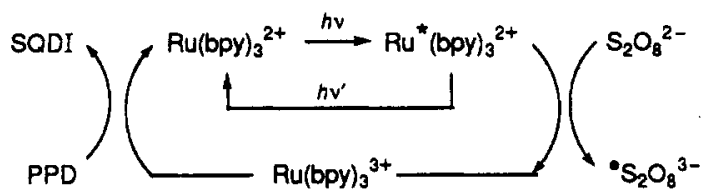

oxydisulfate anion. The resulting ruthenium(III) complex then oxidizes $p$-phenylenediamine. The reduced ruthenium complex may be excited again, oxidized by further peroxydisulfate and again be reduced by $p$-phenylenediamine. This cycle is interrupted only by the consumption of peroxydisulfate (usually an excess of p-phenylenediamine was applied) or by stopping the irradiation.

The peroxydisulfate radical, $\cdot \mathrm{S}_{2} \mathrm{O}_{8}{ }^{3-}$, decomposes to produce inert sulfate and sulfate radical:

$$
{ }^{-} \mathrm{S}_{2} \mathrm{O}_{8}{ }^{3-} \rightarrow \mathrm{SO}_{4}{ }^{2-}+\mathrm{SO}_{4}{ }^{--}
$$

This radical may dimerize to regenerate peroxydisulfate or oxidize p-phenylenediamine:

$$
\begin{gathered}
\mathrm{SO}_{4}{ }^{-}+{ }^{-} \mathrm{SO}_{4}{ }^{-} \rightarrow \mathrm{S}_{2} \mathrm{O}_{8}{ }^{2-} \\
\mathrm{PPD}+{ }^{-} \mathrm{SO}_{4}^{-} \rightarrow \mathrm{SQDI}+\mathrm{SO}_{4}{ }^{2-}
\end{gathered}
$$

or oxidize $\mathrm{Ru}(\mathrm{bpy})_{3}{ }^{2+}$ to form $\mathrm{Ru}(\mathrm{bpy})_{3}{ }^{3+} .26$ With reaction 4 , which usually dominates, one excited ruthenium(II) molecule leads to the formation of two molecules of $p$-semiquinonediimine. In the presence of a high excess of PPD almost no QDI is formed because the quinonediimine produced then reacts with excess $p$-phenylenediamine to give two molecules of $p$-semiquinonediimine.

According to Scheme 2, the rate of the formation of SQDI should depend on the light intensity, the quantum yield of the quenching reaction with peroxydisulfate and on the rate of oxidation of PPD by $\mathrm{Ru}$ (bpy) ${ }_{3}{ }^{3+}$. The reaction time decreased with increasing light intensity until a limiting value was obtained. This saturation effect was due to the high light intensity employed. Under the conditions of the experiments described in this paper, i.e., using high light intensity, the quasi-stationary concentration of $R u$ (bpy) ${ }_{3}{ }^{3+}$ was determined by the rates of both the quenching process and the redox reaction between $P P D$ and $R u(b p y){ }_{3}{ }^{3+}$. To obtain more information about the mechanism, these reactions were studied separately.

Quenching of $\mathrm{Ru}^{*}$ (bpy) ${ }_{3}^{2+}$ by Peroxydisulfate. As $R u(b p y)_{3}{ }^{2+}$ and $R u(b p y))_{3}{ }^{3+}$ exhibit different UV-vis spectra, the formation of $\mathrm{Ru}(\mathrm{bpy})_{3}{ }^{3+}$ could easily be followed spectrophotometrically (see Figure 6). The luminescence quenching studies were made in aqueous solutions of $\mathrm{Ru}$ (bpy) ${ }_{3}{ }^{2+}$. The quenching rate constant, $k_{\mathrm{q}}=1.4 \times 10^{9} \mathrm{M}^{-1} \mathrm{~s}^{-1}$, determined for this process is in good agreement with literature values. ${ }^{39}$ The reaction is believed to generate ${ }^{\cdot} \mathrm{S}_{2} \mathrm{O}_{8}{ }^{3-}$ and $\mathrm{Ru}(\text { bpy })_{3}{ }^{3+}$. 
TABLE 1

\begin{tabular}{lrcll}
\hline & $\tau / \mathrm{s}$ & {$\left[\mathrm{Ru}(\mathrm{bpy}) 3^{2+}\right] / \mathrm{M}$} & {$\left[\mathrm{K}_{2} \mathrm{~S}_{2} \mathrm{O}_{8}\right] / \mathrm{M}$} & {$[\mathrm{PPD}] / \mathrm{M}$} \\
\hline$a$ & 0 & $1.33 \times 10^{-4}$ & 0 & 0 \\
$b$ & 30 & $1.33 \times 10^{-4}$ & $6.67 \times 10^{-4}$ & 0 \\
$c$ & 30 & $1.33 \times 10^{-4}$ & $6.67 \times 10^{-4}$ & $3.33 \times 10^{-5}$ \\
$d$ & 30 & $1.33 \times 10^{-4}$ & $6.67 \times 10^{-4}$ & $6.67 \times 10^{-5}$ \\
$e$ & 30 & $1.33 \times 10^{-4}$ & $3.33 \times 10^{-5}$ & $3.33 \times 10^{-4}$
\end{tabular}

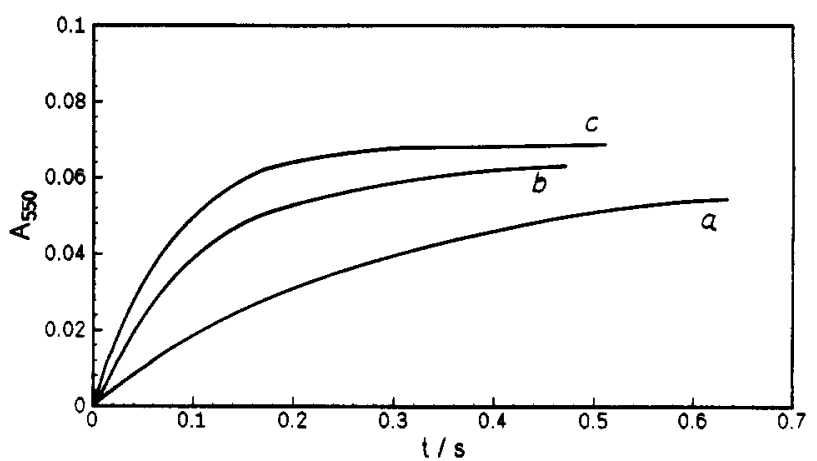

Figure 7. Absorbance-time curves for the oxidation of $N, N$-diethyl-pphenylenediamine (varying concentration) by a mixture of $\mathrm{K}_{2} \mathrm{~S}_{2} \mathrm{O}_{8}(8.33$ $\left.\times 10^{-5} \mathrm{M}\right)$ and $\mathrm{Ru}(\mathrm{bpy}) 3_{3}{ }^{2+}\left(3.3 \times 10^{-5} \mathrm{M}\right)$ after illuminating it for 20 s. $\lambda=550 \mathrm{~nm}, l=0.22 \mathrm{~cm},[P P D]=1.33 \times 10^{-4} \mathrm{M}(\mathrm{a}), 3.3 \times 10^{-4}$ $M(b)$ and $6.67 \times 10^{-4} \mathrm{M}(\mathrm{c})$

Although there is good kinetic evidence for $\cdot \mathrm{S}_{2} \mathrm{O}_{8}{ }^{3-}$ having a finite lifetime ${ }^{29}$ some researchers such as Wilmarth and Haim ${ }^{40}$ have noted that peroxydisulfate reactions with transition-metal complexes are not simple one-electron-transfer reactions but rather involve the reductive cleavage of the peroxydisulfate $\mathrm{O}-\mathrm{O}$ bond to generate sulfate ion and sulfate radical. Furthermore, there is some kinetic evidence for the presence of ion pairs in the Ru(bpy) ${ }_{3}{ }^{2+} / \mathrm{S}_{2} \mathrm{O}_{8}{ }^{2-}$-system. ${ }^{28}$ However, complexes of this kind should not affect the kinetics of the oxidation of $p$-phenylenediamine by either $\mathrm{S}_{2} \mathrm{O}_{8}{ }^{2-}$ or $\mathrm{Ru}(\mathrm{bpy}){ }_{3}{ }^{3+}$.

Oxidation of $N, N$-Diethyl- $p$-phenylenediamine by $R u(b p y) 3^{3+}$, The time scale for the reaction between PPD and $R u(b p y) 3_{3}{ }^{3+}$ was in the range of seconds or milliseconds. Therefore, all experiments were performed with a stopped-flow apparatus. The course of the reaction was followed at $550 \mathrm{~nm}$ so as to record the formation of SQDI. Some examples are shown in Figure 7.

$\mathrm{Ru}$ (bpy) $3^{3+}$ was prepared immediately before mixing the reactants by irradiation of an aqueous solution of $R u(b p y) 3_{3}{ }^{2+}$ in the presence of an excess of peroxydisulfate. The concentration of the ruthenium(III) complex formed was determined as described below. Under certain conditions almost all the Ru(bpy) $3_{3}{ }^{2+}$ could be converted into $\mathrm{Ru}(\mathrm{bpy})_{3}{ }^{3+}$. The sulfate radical could either oxidize water or according to eq 3 synproportionate to peroxydisulfate. Residual peroxydisulfate did not disturb because it oxidizes $p$-phenylenediamines much slower than $R u$ (bpy) $3^{3+} .{ }^{39}$ It was not necessary to maintain the ionic strength at a constant level because one of the reactants (PPD) is uncharged (as proved by the $\mathrm{pH}$ dependence of the reaction).

The order of the redox reaction between $N, N$-diethyl-pphenylenediamine and $\mathrm{Ru}(\mathrm{bpy}) 3^{3+}$ was determined by carrying out several experiments, keeping the concentration of one reactant constant and varying the concentration of the other. The $\log / \log$ plots of the initial reaction rate against the initial concentration of the appropriate reactants showed that the reaction was first order in both PPD and Ru(bpy) ${ }_{3}{ }^{3+}$.

The initial reaction rate $(\mathrm{d} A / \mathrm{d} t)_{0}$ as well as the initial concentration of $R u(b p y){ }_{3}{ }^{3+}$ was obtained from a plot of the reaction rate $(\mathrm{d} A / \mathrm{d} t)$ against the corresponding absorbance $(A)$ as demonstrated in Figure 8 (see derivation below). The reaction rate $(\mathrm{d} A / \mathrm{d} t)$ was determined by means of a mirror ruler at different points of the measured absorbance time curve. Extrapolation to $A=0$ gave the initial reaction rate $(\mathrm{d} A / \mathrm{d} t)_{0}$ while the absorbance at $\mathrm{d} A / \mathrm{d} t=0$ (which should equal $A_{\infty}$ as long as

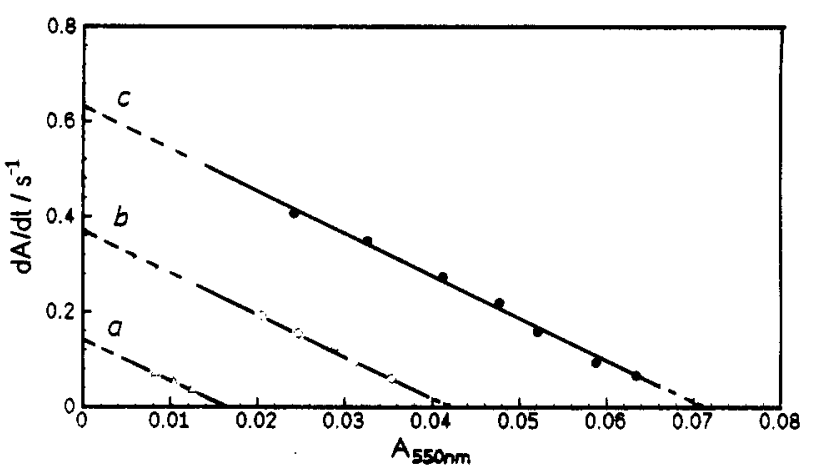

Figure 8. Plot of the formation rate of SQDI $(d A / \mathrm{d} t)$ against the corresponding absorbance $\left(A_{5 s 0 \mathrm{~mm}}\right) . \lambda=550 \mathrm{~nm}, l=0.22 \mathrm{~cm}$ (see Table 2).

TABLE 2

\begin{tabular}{cccc}
\hline & {$\left[\mathrm{Ru}(\mathrm{bpy})_{3}{ }^{2+}\right] / \mathrm{M}$} & {$\left[\mathrm{K}_{2} \mathrm{~S}_{2} \mathrm{O}_{8}\right] / \mathrm{M}$} & {$[\mathrm{PPD}] / \mathrm{M}$} \\
\hline$a$ & $1 \times 10^{-5}$ & $2.5 \times 10^{-5}$ & $3.3 \times 10^{-4}$ \\
$b$ & $2 \times 10^{-5}$ & $5.0 \times 10^{-5}$ & $3.3 \times 10^{-5}$ \\
$c$ & $3.3 \times 10^{-5}$ & $8.3 \times 10^{-5}$ & $3.3 \times 10^{-4}$
\end{tabular}

no consecutive reaction such as deamination occurs $)^{36,41,42}$ led to the initial concentration of the ruthenium(III) complex, [Ru(bpy) $\left.{ }^{3+}\right]_{0}$ :

$$
\left[\mathrm{Ru}(\mathrm{bpy}){ }_{3}{ }^{3+}\right]_{0}=A_{\infty} / \epsilon_{\mathrm{S}} l
$$

with $\epsilon_{\mathrm{S}}=1.10 \times 10^{4} \mathrm{M}^{-1} \mathrm{~cm}^{-1}$ at $550 \mathrm{~nm}$ and $l=0.22 \mathrm{~cm}$. As the dark oxidation with residual peroxydisulfate occurred much more slowly than the oxidation with $\mathrm{Ru}(\mathrm{bpy}) 3^{3+}$ (compare the time scale of Figures 2 and 7 ), the autocatalytic formation of SQDI did not affect the results. Furthermore, in the presence of a large excess of $p$-phenylenediamine the formation of QDI could be neglected. Thus, the formation of SQDI occurred predominantly by eq 6 :

$$
\mathrm{PPD}+\mathrm{Ru}(\mathrm{bpy})_{3}{ }^{3+} \stackrel{{ }^{k_{1}}}{\rightarrow} \mathrm{SQDI}+\mathrm{Ru}(\mathrm{bpy})_{3}{ }^{2+}
$$

with the kinetic equation

$$
\begin{aligned}
\mathrm{d}[\mathrm{SQDI}] / \mathrm{d} t= & k_{1}^{\prime}[\mathrm{PPD}]\left[\mathrm{Ru}(\mathrm{bpy})_{3}{ }^{3+}\right] \\
= & k_{1}^{\prime}\left([\mathrm{PPD}]_{0}-[\mathrm{SQDI}]\right)\left(\left[\mathrm{Ru}(\mathrm{bpy})_{3}{ }^{3+}\right]_{0}-\right. \\
{[\mathrm{SQDI}])(7 \mathrm{~b}) } & \\
= & k_{1}^{\prime}[\mathrm{PPD}]_{0}\left[\mathrm{Ru}(\mathrm{bpy})_{3}{ }^{3+}\right]_{0}-k_{1}^{\prime}\left([\mathrm{PPD}]_{0}+\right. \\
& {\left.\left[\mathrm{Ru}(\mathrm{bpy})_{3}{ }^{3+}\right]_{0}\right)[\mathrm{SQDI}]+k_{1}^{\prime}([\mathrm{SQDI}])^{2}(7 \mathrm{c}) }
\end{aligned}
$$

Multiplication by $\epsilon_{S} l$ and neglecting the quadratic term gave the relation between the absorbance change $(\mathrm{d} A / \mathrm{d} t)$ and the corresponding absorbance $(A)$ :

$$
\begin{array}{r}
\mathrm{d} A / \mathrm{d} t=k_{1}^{\prime} \epsilon_{\mathrm{s}} l[\mathrm{PPD}]_{0}\left[\mathrm{Ru}(\mathrm{bpy})_{3}{ }^{3+}\right]_{0}-k_{1}^{\prime}\left([\mathrm{PPD}]_{0}+\right. \\
\left.\left[\mathrm{Ru}(\mathrm{bpy})_{3}{ }^{3+}\right]_{0}\right) A
\end{array}
$$

The rate constant, $k_{1}^{\prime}$, could, therefore, be obtained from the slope of the regression lines in Figure 8. According to eq 8 the intercept at $A=0$ should allow the calculation of the concentration of $\mathrm{Ru}$ (bpy) $3^{3+}$ as long as the formation of QDI can be neglected. Under the experimental conditions the initial concentration $[\mathbf{R u}$ (bpy) $\left.3^{3+}\right]_{0}$ was found to depend on the initial concentration of both $\left[\mathrm{Ru}(\mathrm{bpy})_{3}{ }^{2+}\right]_{0}$ and $\left[\mathrm{S}_{2} \mathrm{O}_{8}{ }^{2-}\right]_{0}$. Table 3 summarizes the effect 
TABLE 3: Effect of $\left[\mathrm{S}_{2} \mathrm{O}_{8}^{2-}\right]$ on $\left[\mathrm{Ru}^{3+}\right]$ Conversion"

\begin{tabular}{llll}
\hline$\left[\mathrm{S}_{2} \mathrm{O}_{8}^{2-}\right]$ & $3.3 \times 10^{-5} \mathrm{M}$ & $2.0 \times 10^{-5} \mathrm{M}$ & $1.0 \times 10^{-5} \mathrm{M}$ \\
{$\left[\mathrm{Ru}^{3+}\right]$} & $3.1 \times 10^{-5} \mathrm{M}$ & $1.8 \times 10^{-5} \mathrm{M}$ & $7.5 \times 10^{-6} \mathrm{M}$ \\
$\%$ & $97 \%$ & $90 \%$ & $75 \%$ \\
0 & {$[\mathrm{PPD}]=3.3 \times 10^{-4} \mathrm{M},\left[\mathrm{Ru}^{2+}\right]=3.3 \times 10^{-5} \mathrm{M}, \mathrm{pH}$, irradiation } \\
time $10 \mathrm{~s}$. &
\end{tabular}

TABLE 4: pH Effect on the $\left[\mathrm{Ru}^{3+} \mathrm{b}\right.$ and $\boldsymbol{k}_{1}^{\prime}$ Valuese

\begin{tabular}{ccc}
\hline $\mathrm{pH}$ & {$\left[\mathrm{Ru}^{3+}\right]_{0} / \mathrm{M}$} & $k_{1}^{\prime} / \mathrm{M}^{-1} \mathrm{~s}^{-1}$ \\
\hline 4 & $2.6 \times 10^{-5}$ & $1.4 \times 10^{4}$ \\
5 & $3.1 \times 10^{-5}$ & $2.6 \times 10^{4}$ \\
6 & $3.2 \times 10^{-5}$ & $8.5 \times 10^{5}$ \\
$a[\mathrm{PPD}]=3.3 \times 10^{-4} \mathrm{M},\left[\mathrm{S}_{2} \mathrm{O}_{8}^{2-}\right]=8.3 \times 10^{-5} \mathrm{M}$ and $\left[\mathrm{Ru}^{2+}\right]=3.3$ \\
$\times 10^{-5} \mathrm{M}$.
\end{tabular}
$\times 10^{-5} \mathrm{M}$.

of $\left[\mathrm{S}_{2} \mathrm{O}_{8}{ }^{2-}\right]_{0}$ on the $\left[\mathrm{Ru}(\mathrm{bpy})_{3}{ }^{3+}\right]$ formation for $\mathrm{pH} 5$, irradiation time $10 \mathrm{~s}$ (with a xenon lamp), and $\left[\mathrm{S}_{2} \mathrm{O}_{8}{ }^{2-}\right]_{0}>\left[\mathrm{Ru}(\mathrm{bpy})_{3}{ }^{2+}\right]_{0}$.

Table 4 summarizes for several $\mathrm{pH}$ values the experimental results for $\left[R u(b p y) ~_{3}{ }^{3+}\right]_{0}$ and $k_{1}^{\prime}$. The dramatic increase of the rate constant with increasing $\mathrm{pH}$ results from the much higher reactivity of the neutral $p$-phenylenediamine molecule compared to that of the monoprotonated form. However, as the reaction at $\mathrm{pH}>7$ became too fast to be studied with simple stopped-flow techniques, the detailed $\mathrm{pH}$ dependence of the reaction rate could not be obtained.

Mechanism of the Photocatalyzed Reaction. With the knowledge of the intrinsic decay rate constant $k^{i}$ of the excited bipyridyl ruthenium(II) complex and the rate constant of the quenching process caused by peroxydisulfate, the stationary concentration of the excited ruthenium(II) complex $\mathrm{Ru}^{*}(\mathrm{bpy})_{3}{ }^{2+}$ can be estimated. If $I$ is the intensity of the light source, then

$$
\left[\mathrm{Ru}^{*}(\mathrm{bpy})_{3}{ }^{2+}\right]_{\text {stat }} \propto \frac{I\left[\mathrm{Ru}(\mathrm{bpy})_{3}{ }^{2+}\right]}{k^{j}+k_{\mathrm{q}}\left[\mathrm{S}_{2} \mathrm{O}_{8}{ }^{2-}\right]}
$$

In the absence of $p$-phenylenediamine, the concentration of Ru(bpy) $3^{3+}$ is given by

$$
\left[\mathrm{Ru}(\mathrm{bpy})_{3}{ }^{3+}\right] \propto \frac{I\left[\mathrm{Ru}(\mathrm{bpy})_{3}{ }^{2+}\right] k_{\mathrm{q}}\left[\mathrm{S}_{2} \mathrm{O}_{8}{ }^{2-}\right]}{k^{\mathrm{j}}+k_{\mathrm{q}}\left[\mathrm{S}_{2} \mathrm{O}_{8}{ }^{2-}\right]}
$$

With a high concentration of peroxydisulfate, the formation of $\mathrm{Ru}$ (bpy) ${ }_{3}{ }^{3+}$ may become the dominant decay path and the final concentration of the ruthenium(III) complex may approach the initial concentration of $\mathrm{Ru}(\mathrm{bpy})_{3^{2+}}$. The concentration of peroxydisulfate remains almost unchanged.

Because of the rather long lifetime of the excited ruthenium complex ( $\tau \sim 620 \mathrm{~ns}$ in degassed solutions) ${ }^{12}$ a concentration of peroxydisulfate as low as $10^{-4} \mathrm{M}$ was sufficient to yield a ruthenium(III) complex which catalyzed the redox reaction between PPD and $\mathrm{S}_{2} \mathrm{O}_{8}{ }^{2-}$. Assuming that the quantum yield for $\mathrm{Ru}^{*}(\mathrm{bpy}) 3^{2+}$ formation is $1,{ }^{16}$ with the intrinsic decay constant $k^{\mathrm{i}}=1 / \tau \sim 1.6 \times 10^{6} \mathrm{~s}^{-1}$ and the almost diffusion-limited rate constant $k_{\mathrm{q}}=1.4 \times 10^{9} \mathrm{M}^{-1} \mathrm{~s}^{-1}$, the percentage of quenching could be estimated by the equation

$$
\phi_{\mathrm{q}} \simeq \frac{k_{\mathrm{q}}\left[\mathrm{S}_{2} \mathrm{O}_{8}{ }^{2-}\right]}{k^{\mathrm{j}}+k_{\mathrm{q}}\left[\mathrm{S}_{2} \mathrm{O}_{8}{ }^{2-}\right]}
$$

At a peroxydisulfate concentration of $10^{-3} \mathrm{M}$, a yield of $\phi_{q}=0.5$ should therefore be obtained.

In the presence of an oxidizable agent such as p-phenylenediamine, the ruthenium(III) complex will be reduced and thus a new quasi-stationary concentration of $\mathrm{Ru}(\mathrm{bpy}) 3^{3+}$ will be established. The higher the value of the rate constant $k_{1}^{\prime}$ of the
SCHEME 3

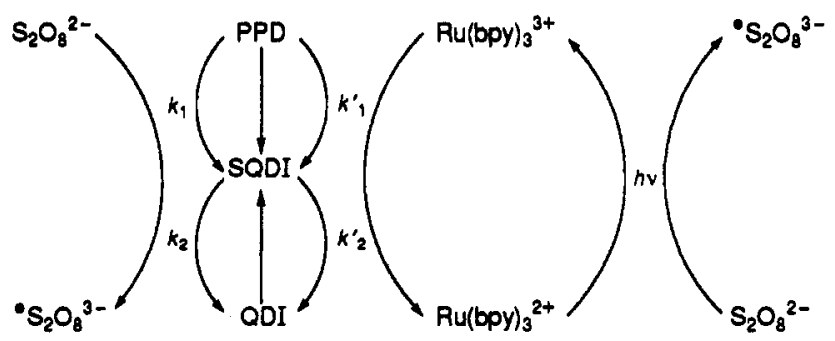

redox reaction between $\mathrm{PPD}$ and $\mathrm{Ru}(\mathrm{bpy})_{3}{ }^{3+}$ the lower will be $\left[\mathrm{Ru}(\mathrm{bpy}) 3^{3+}\right]_{\text {satat }}$. The formation rate of SQDI given by eq 7 may therefore depend on the concentration of both $\mathrm{Ru}(\mathrm{bpy})_{3}{ }^{2+}$ and $\mathrm{S}_{2} \mathrm{O}_{8}{ }^{2-}$. This may be independent of the concentration of PPD if the formation of $\mathrm{Ru}(\mathrm{bpy})_{3}{ }^{3+}$ occurs slowly.

Thus, the overall reaction (dashed curve in Figure 5) seems to be determined by the quenching process shown in Scheme 2. But the situation is not so simple. As the concentration of $R u(b p y) 3_{3}{ }^{3+}$ remains very low (it cannot exceed $\left[R u(b p y){ }_{3}{ }^{2+}\right]_{0}$ ), the photocatalyzed oxidation of $p$-phenylenediamine by peroxydisulfate cannot become a very fast reaction. Therefore the autocatalytic oxidation of SQDI by $\mathrm{S}_{2} \mathrm{O}_{8}{ }^{2-}$ according to Scheme 1 will compete more successfully with the photocatalytic reaction. This explains the slight sigmoidal course of the dashed line in Figure 5. This effect disappeared with a higher concentration of $\mathrm{Ru}(\mathrm{bpy})_{3}{ }^{2+}$, but the influence of the autocatalytic reaction could not be completely suppressed, even with a very high concentration of $\mathrm{Ru}(\mathrm{bpy}) 3^{2+}$. Of course, $\mathrm{Ru}(\mathrm{bpy}){ }_{3}{ }^{3+}$ may also react with SQDI, thus supporting the autocatalytic reaction. The kinetic equation for the formation of SQDI is therefore not just given by the simple eq 7a but by eq $12.2^{29}$ At the beginning of the reaction,

$$
\begin{array}{r}
\mathrm{d}[\mathrm{SQDI}] / \mathrm{d} t=2 k_{1}[\mathrm{PPD}]\left[\mathrm{S}_{2} \mathrm{O}_{8}{ }^{2-}\right]+2 k_{2}[\mathrm{SQDI}]\left[\mathrm{S}_{2} \mathrm{O}_{8}{ }^{2-}\right]+ \\
k_{1}^{\prime}[\mathrm{PPD}]\left[\mathrm{Ru}(\mathrm{bpy})_{3}{ }^{3+}\right]+k_{2}^{\prime}[\mathrm{SQDI}]\left[\mathrm{Ru}(\mathrm{bpy})_{3}{ }^{3+}\right]
\end{array}
$$

the concentration of SQDI is very low. The initial reaction rate is therefore determined by the terms containing the rate constants $k_{1}$ and $k_{1}^{\prime}$. As $k_{1}^{\prime} \gg k_{1}$ and the concentration of $\mathrm{Ru}(\mathrm{bpy})_{3}{ }^{3+}$ is kept constant by regeneration with peroxydisulfate and light, the term $k_{1}^{\prime}\left[\mathrm{Ru}(\mathrm{bpy}){ }_{3}{ }^{3+}\right]$ may exceed the term $k_{1}\left[\mathrm{~S}_{2} \mathrm{O}_{8}{ }^{2-}\right]$, although the concentration of peroxydisulfate is much higher than that of the ruthenium(III) complex. The higher the quasi-stationary concentration of $\mathrm{Ru}(\mathrm{bpy}){ }^{3+}$, the more effective will be the photocatalysis. After the formation of sufficient SQDI, the terms with the rate constants $k_{2}$ and $k_{2}^{\prime}$ will dominate and an autocatalytic increase of the reaction rate may occur. But as the rate constant $k_{2}^{\prime}$ is not much higher than the rate constant $k_{2}$, the term $k_{2}^{\prime}\left[\mathrm{Ru}(\mathrm{bpy})_{3}{ }^{3+}\right]$ will not exceed the term $2 k_{2}\left[\mathrm{~S}_{2} \mathrm{O}_{8^{2}}{ }^{2-}\right]$ if the concentration of the ruthenium complex is low. Therefore, the autocatalytic course of the reaction will not be accelerated by irradiation unless the concentration of the ruthenium complex is fairly high (at least $10 \%$ of peroxydisulfate).

The complete mechanism for both the autocatalytic dark reaction and the photocatalyzed oxidation is displayed in Scheme 3. In contrast to the acceleration with oxidants such as hexacyanoferrate(III) (see Figure 3), a major shortening of the induction period does not need a high concentration of the ruthenium catalyst. The concentration of the rapidly formed SQDI, which starts the autocatalytic reaction, is not limited by the supporting oxidant but increases continuously via the irradiation. However, during the course of the reaction the autocatalysis becomes more and more important and may eventually dominate. SQDI is then produced predominantly by peroxydisulfate and no longer by $\mathrm{Ru}(\mathrm{bpy})_{3}{ }^{3+}$.

Under the experimental conditions no $\mathrm{Ru}(\mathrm{bpy})_{3}{ }^{2+}$ is consumed, i.e., the ruthenium complex is a real catalyst. This is demonstrated by the spectra displayed in Figure 6 . The slight increase of 
absorbance at the wavelength of maximum absorbance of $\mathrm{Ru}$ (bpy) ${ }_{3}{ }^{2+}$ is caused by the absorption of SQDI. However, complete recovery of the initial concentration of $\mathrm{Ru}(\mathrm{bpy})_{3}{ }^{2+}$ after stopping the irradiation is sometimes not achieved, because $R u(b p y) 3_{3}{ }^{3+}$ may react not only with PPD but also with water. Then some ligand dissociation occurs and the free bipyridine may undergo several subsequent reactions. During fairly short reaction times this parallel reaction can virtually be neglected, particularly in the presence of a high excess of PPD.

\section{Conclusion}

The slow oxidation of $N, N$-diethyl-p-phenylenediamine by peroxydisulfate can be strongly enhanced by the addition of tri2,2'-bipyridylylruthenium(II) together with irradiation of the solution because of the formation of the rapidly oxidizing ruthenium(III) complex. This procedure may also be applied to many other redox reactions with peroxydisulfate as oxidant. All aromatic amines in particular should be oxidized rapidly in the presence of $R u(b p y)_{3}{ }^{2+}$ and light. This method would therefore be applicable to the destruction of harmful aromatic compounds in environmental protecting processes. Moreover, the present reaction may be taken as a model for the study of photoinduced two-step redox reactions in biological systems. By using variously substituted $p$-phenylenediamines, the kinetics of the autocatalytic reaction can be varied over a wide range, which may allow the rate-determining step to be determined. Thus, a thorough study of photocatalyzed reactions will be possible.

Acknowledgment. The authors would like to express their thanks to the Fonds der Chemischen Ind. and to Fundaçao Calouste Gulbenkian for financial support.

\section{References and Notes}

(1) Paris, J. P.; Brandt, W. W. J. Am. Chem. Soc. 1959, 81, 5001.

(2) Baker, D. C.; Crosby, C. A. Chem. Phys. 1974, 4, 428.

(3) De Cola, L.; Belser, P. Ebmeyer, F.; Barigelletti, F.; Vogtle, F.; Zelewsky, A.; Balzani, V. Inorg. Chem. 1990, 29, 495. 77.

(4) Kim, H. B.; Kitamura, N.; Tazuke, S. Chem. Phys. Lett. 1988, 143,

(5) Lumpin, R. S.; Kober, E. M.; Worl, L. A.; Murtaza, Z.; Meyer, T. J. J. Phys. Chem. 1990, 94, 239.
(6) Juris, A.; Balzani, V. Coord. Chem. Rev. 1988, 84, 85.

(7) Krausz, E.; Ferguson, J. Prog. Inorg. Chem. 1989, 37, 293.

(8) Kemp, T. J. Prog. React. Kinet. 1980, 10, 301. 1889.

(9) Kojima, H.; Sato, N.; Kawamoto, J.; Iyoda, J. Chem. Lett. 1989, 10,

(10) Kaneko, M.; Iwahata, S.; Asakura, T. Photochem. Photobiol. 1992, 55,505 .

(11) Kalyanasundaram, K. Coord. Chem. Rev. 1982, 46, 159.

(12) Hoffman, M. Z. J. Phys. Chem. 1988, 92, 3458.

(13) Balzani, V.; Bolleta, F.; Gandolfi, M. T.; Maestri, M. Top. Curr. Chem. 1978, 75, 1.

(14) Meyer, T. J. Pure Appl. Chem. 1986, 9, 1193.

(15) Sutin, N. J. Photochem. 1979, 10, 19.

(16) Kayanasundaram, K.; Grätzel, M.; Pelizzetti, E. Coord. Chem. Rev. 1986, 69, 57.

(17) Meyer, T. J. Acc. Chem. Res. 1989, 22, 164

(18) Garrera, H. A.; Osponer, H. E.; Garcia, N. A.; Cosa, J. L.; Previtali, C. M. J. Photochem. 1986, 33, 257.

(19) Balzani, V.; Scandola, F.; Orlandi, G.; Sabbatini, N.; Indelli, M. T.

J. Am. Chem. Soc. 1981, 103, 3370.

(20) Marcus, R. A.; Sutin, N. Bioch. Biophys. Acta 1985, 811, 265.

(21) De Armond, M. K.; Myrick, M. L. Acc. Chem. Res. 1989, 22, 364.

(22) Rehm, D.; Weller, A. Isr. J. Chem. 1970, 8, 259.

(23) Minisci, T.; Citterio, A.; Giordano, C. Acc. Chem. Res. 1983, 16, 27.

(24) White, H. S.; Bard, A. J. J. Am. Chem. Soc. 1982, 104, 6891.

(25) Nishida, S.; Kimura, M. J. Chem. Res. 1986, 336.

(26) Nishida, S.; Kimura, M. Bull. Chem. Soc. Jpn. 1987, 60, 2367.

(27) Bolletta, F.; Giano, M.; Balzani, V.; Serpone, N. Inorg. Chim. Acta $1982,62,207$.

(28) Fürholz, U.; Haim, A. Inorg. Chem. 1987, 26, 3243.

(29) Nickel, U.; Haase, E.; Thormann, B. Z. Phys. Chem. 1991, 170, 159.

(30) Kobayashi, H.; Sakai, S.; Ohno, T.; Mizusawa, S. J. Photogr. Sci. 1986, 34, 53.

(31) Nickel, U.; Klein, J. J. Imag. Sci. 1991, 36, 151.

(32) Burgess, J.; Hubbard, C. D. Inorg. Chim. Acta 1982, 64, 71.

(33) Nickel, U. Ber. Bunsen-Ges. Phys. Chem. 1981, 85, 266.

(34) Patat, F.; Prölss, H. Ber. Bunsen-Ges. Phys. Chem. 1967, 71, 1095.

(35) Nomiya, K.; Kobayashi, H.; Miwa, M. Bull. Chem. Soc. Jpn. 1983, $56,2272$.

(36) Nickel, U.; Kemnitz, K.; Jaenicke, W. J. Chem. Soc., Perkin Trans. 2, 1978, 1188.

(37) Michaelis, L.; Schubert, M. P.; Granick, S. J. Am. Chem. Soc. 1939, 61,1981 .

(38) Nickel, U.; Haase, E.; Jaenicke, W. Ber. Bunsen-Ges. Phys. Chem. $1977,81,849$.

(39) Kimura, M.; Nishida, S. J. Chem. Soc., Dalton Trans. 1985, 355.

(40) Wilmarth, W. K.; Haim, A. Peroxide Reaction Mechanism; Edwards, J. O., Ed.; Interscience: New York, 1961.

(41) Tong, L. K. J. J. Phys. Chem. 1954, 58, 1090.

(42) Nickel, U.; Jaenicke, W. J. Chem. Soc., Perkin Trans. 2 1980, 1601. 